\title{
UNUSUAL USE OF INDUSTRIAL ROBOTS
}

\author{
BARBORAK, O.; BARTOSOVA, L. \& SNAHNICAN, F.
}

Abstract: This paper is about theoretical analysis of robot movements and their subsequent use in unusual fields of industrial production. Handled object, its material constitution, mechanical properties and available working space determine their use in special technology, textile and clothing industry and other non-engineering departments.

Key words: industrial robot, manipulator, special technology, textile industry
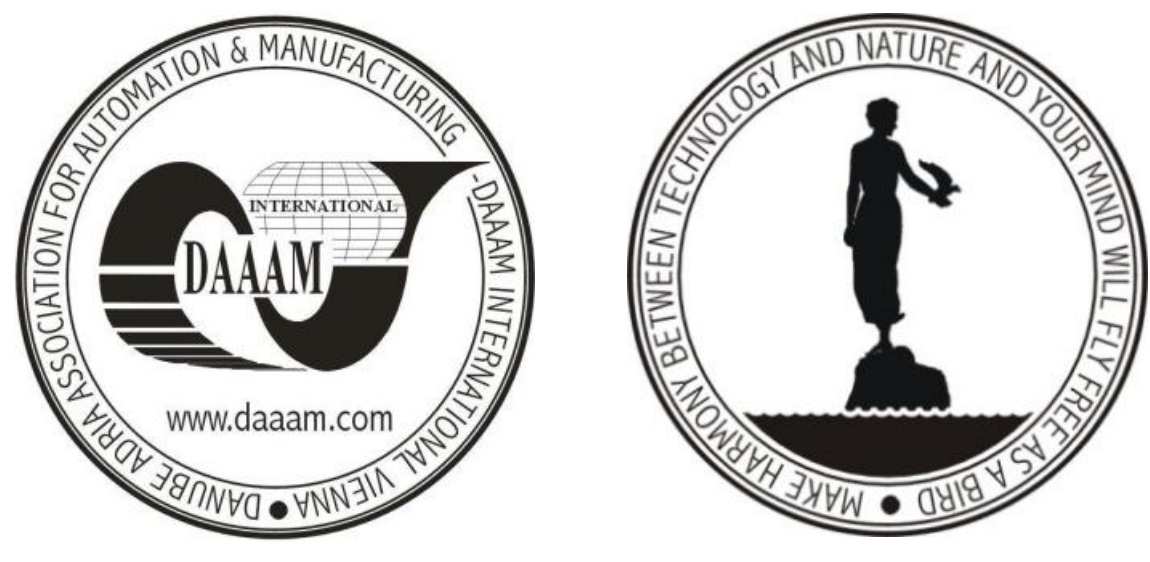

Authors' data: Associate Prof. PhD Eng. Barborak, O[to]; Eng. Bartosova, L[enka]; Snahnican, F[rantisek]. Alexander Dubcek University of Trencin, Studentska 2, 911 50, Trencin, Slovak Republic

This Publication has to be referred as: Barborak, O[to]; Bartosova L[enka] \& Snahnican, F[rantisek] (2011).Unusual Use of Industrial Robots, Chapter 18 in DAAAM International Scientific Book 2011, pp. 215-226, B. Katalinic (Ed.), Published by DAAAM International, ISBN 978-3-901509-84-1, ISSN 1726-9687, Vienna, Austria DOI: 10.2507/daaam.scibook.2011.18 


\section{Introduction}

Intention of using industrial robots and manipulators in industrial departments is being realized in Slovak Republic for past couple of decades. An original purpose of commissioning the robot in an engineering production has been enlarged also for the area of a consumer industry as well as in other manufacturing industries. At present this intention and trend is very intensive, mainly due to new technologies and a higher electronization and automation of manufacturing industries and production lines. In addition to automobile industry, the robot is used in all manufacturing industries, and not only engineering ones.

\section{Basic aspects of judging robots and manipulators}

Industrial robots are very complex machines. Their construction and components vary, depending on their practical use. This composition is unique for every industry, but every robot is composed of several common parts. That is why it is important to possess the basic knowledge of robotics, such as working space, degrees of freedom, structure of individual parts, kinematic and dynamic structures and characteristic technical properties of handled objects.

Mutual movability of items, creating a kinematic pair, is defined by number of degrees of freedom and it complies with number of autonomous simple motions (translating and rotating ones), which the both items can perform vis-à-vis.

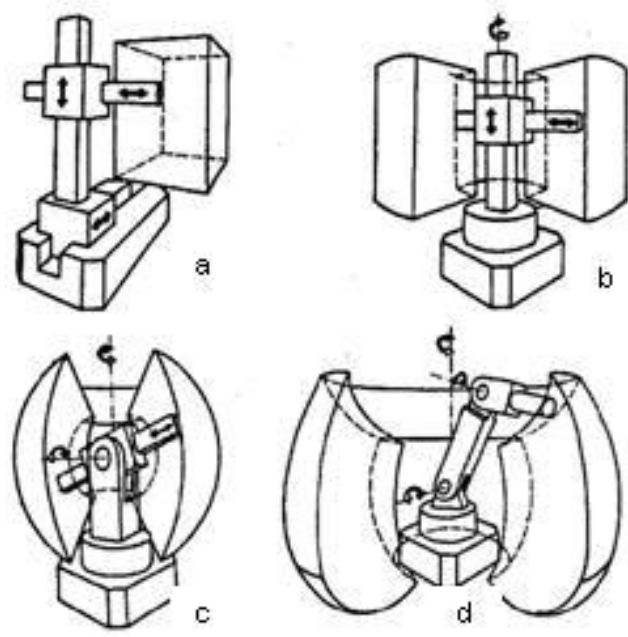

Fig.1. Examples of robot working spaces: a- Cartesian b- cylindrical c- spherical dangular

Any position of the handled object in a space is generally defined by six axes.

- Three of them define the position of the center of gravity, $S$, of the object in a rigid coordinate system $0, \mathrm{x}, \mathrm{y}, \mathrm{z}$

- And other three define the orientation. The term orientation comprises a turning of the object in accordance with axes of coordinate system $\mathrm{S}, \mathrm{x}, \mathrm{y}, \mathrm{z}$, which is dragged together with an object and its axis is parallel with axis of a rigid coordinate system (Fig.2). 


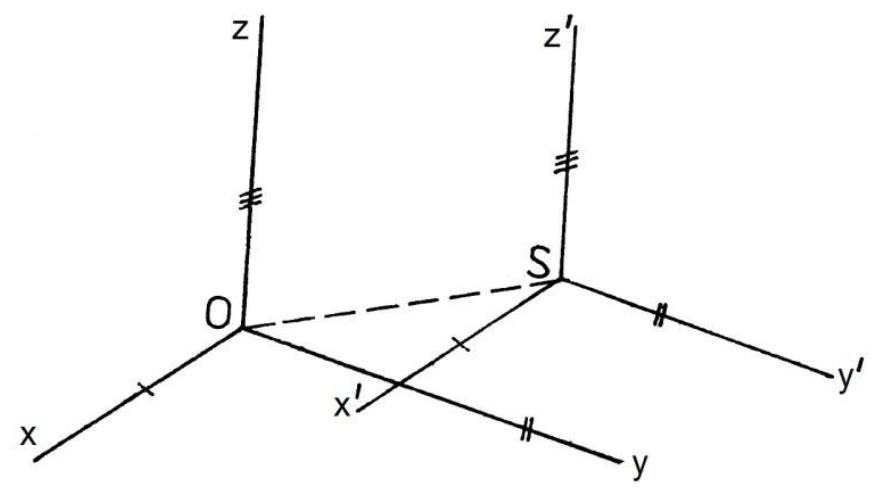

Fig. 2. Position of the center of gravity

It is possible to perform a general motion of a working item of the robot through kinematic chains with 6 degrees of freedom, for example robot CINCINNATI (Fig.3) - contains 6 kinematic pairs (rotating).

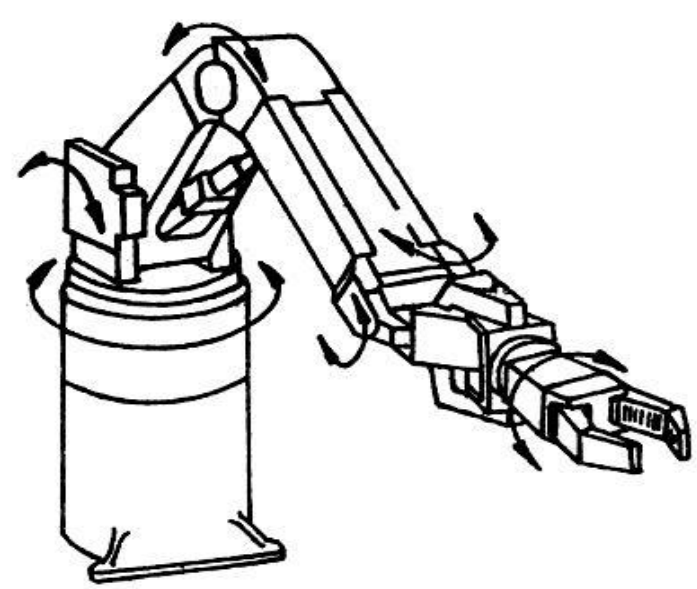

a

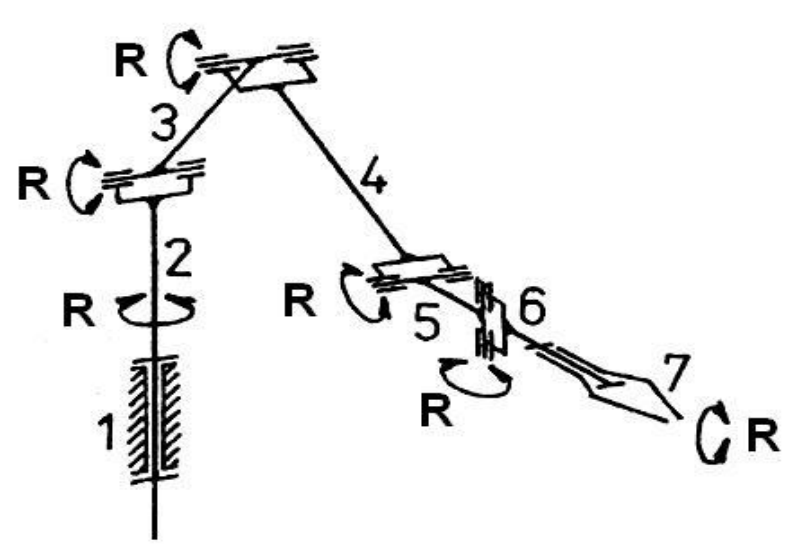

b

Fig. 3. Robot Cincinnati, $6^{\circ}$ of freedom

Robots and manipulators with more than 6 degrees of freedom (Fig.4) are usually designed for handling with objects in hardly accessible areas. E.g. kinematic chain with $8^{\circ}$ of freedom - contains 5 rotating and 3 translating pairs.
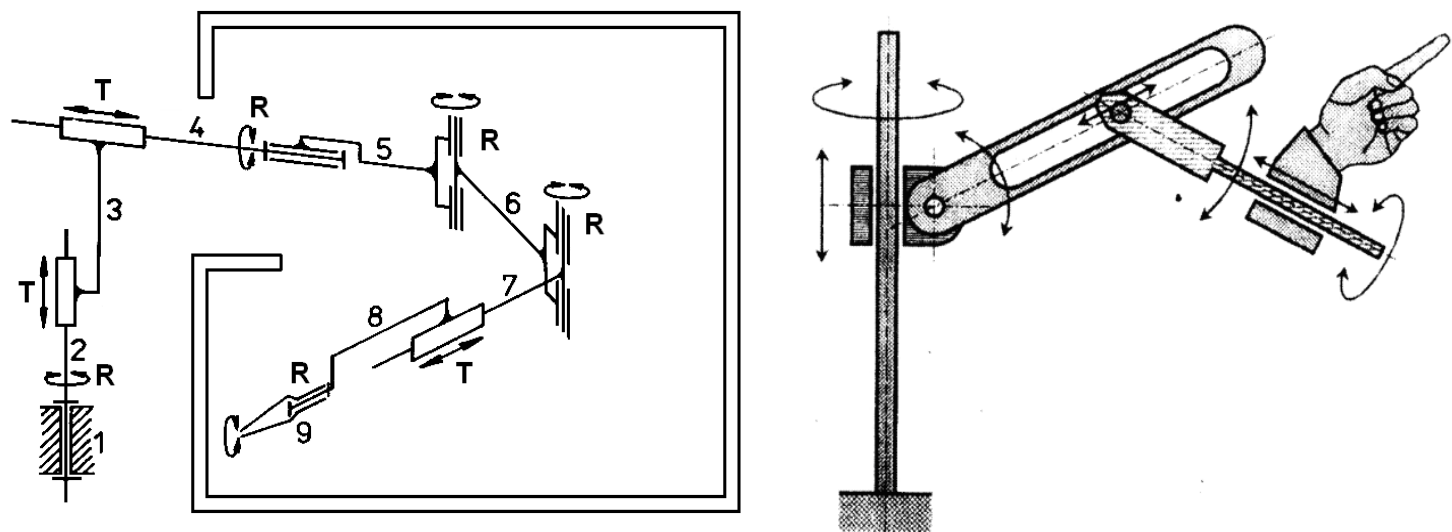

Fig.4. Examples of kinematical chains with sliding and rotational links 
The main views in selecting a kinematic structure of the robot involve:

- Required trajectory of the gravity center of a handled object,

- Accuracy of positioning in removing the gravity center of the object,

- Orientation of the object relating a dragged coordination system,

- Drives, kinetic units and their design,

Examples of chains with labeling the sequence of kinematic pairs and a nature of motions are shown in the picture 8 (all of them have $3^{\circ}$ of freedom, $\mathrm{R}$-rotational link, T- translational link):

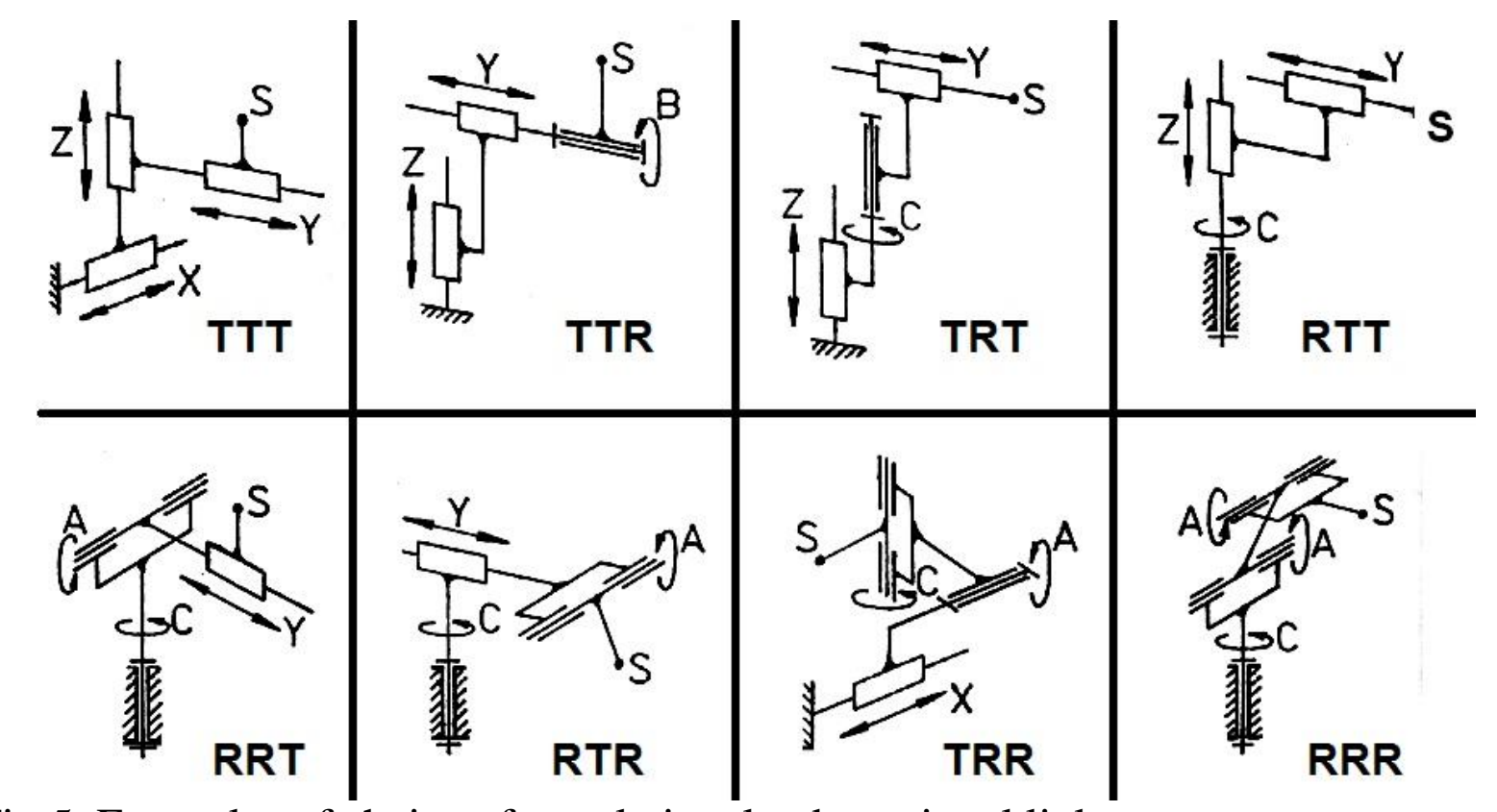

Fig.5. Examples of chains of translationaland rotational links

To all of the above mentioned 8 types of kinematic chains appertain $3^{3}=27$ possibilities of particular arrangements in accordance with a position of axis of translating and rotational motions.

Then the total is 216 possible kinematic chains. Through the combination of links, several working spaces will be achieved, in which robots are able to perform their functional motions (Fig.5)

a) For a TTT arrangement, a working space of a robot is a prism (MANTA robots),

b) For a RTT arrangement, a working space of a robot is a cylindrical segment (VERSATRAN robots),

c) For a RRT arrangement a working space of a robot is a spherical segment (UNIMATE),

d) For a RRR arrangement a working place of a robot is a torus (CINCINNATI, ASEA). (Barborak, 2009)

By learning these basic principles of robotics, one can advance to the analysis of structural solution, designing of specific robotic constructions. Good example can be the design and 3D model of a remote control robot with an assault rifle (Fig.6). (Liptak, 2006) 


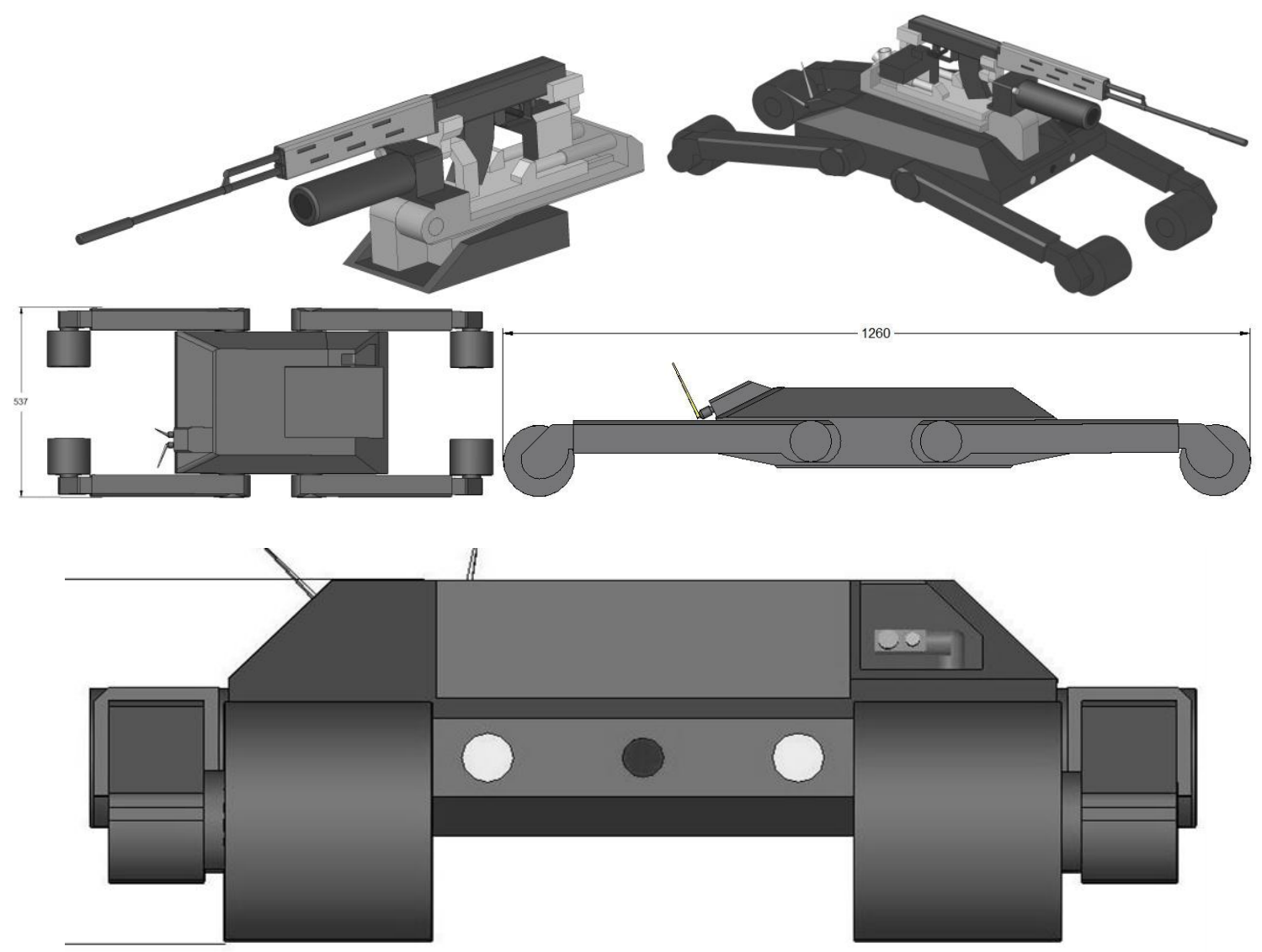

Fig. 6. Study of weapon position on a mobile robot

When doing kinematic and dynamic studies the test conditions were modelled in such way that we could simulate the possibilities of robot motions which could be used in the fields in which they have not been used so far on a mass scale. We considered especially textile and clothing production, where it is often manipulated with pliable, permeable and unstable textile material. The next research of special robots use was aimed at special technology field, in which we often see manipulation with objects in difficult terrain conditions, and with hazardous materials. The research was concentrated in both fields on terminal robot effectors. Partial results of the research and development are presented in the following chapters and they present a new view on robot elements application in nontraditional technologies. Existing responses to partial results can be inspiring for further solutions of this issue.

\section{Use of robots in textile production}

Technologies in textile industry are miscellaneous and they belong to the most complicated ones in industrial operations. Textile technology can be classified according to processing methods into raw textile material technology, spinning technology, textile production and textile proofing.

A characteristic element of textile machinery production is continuity.Operations are conducted on machines practically continuously and are affected by different failures and transient conditions, which can occur during production operation or manipulation with material, semi-finished product or finished textile product. 
The working process itself is automated by typical automation elements, which are incorporated into machines. These are for example regulation of winding and drawing off mechanisms, automatic regulation of material weight, or regulation in sliver production.

While introducing robotics into textile industry several difficulties occur. They include the consequence of specific properties of processed materials and unique aspects of production conditions. These are:

- noticeably predominating one dimension (length) compared to other dimensions,

- considerable anisotropy (dependence of physical properties of material on direction) and broad scatter of mechanical properties,

- very heterogeneous structure of textile products, made from a huge number of fibres bound together,

- low toughness of textile materials and products, i.e. a large compliance and tendency towards mechanical damage,

- special climatic conditions, required in textile production,

Before mentioned circumstances represent limiting factors inintroduction of robotsThese include:

- gripping devices, which were developed in other fields (those used in engineering fields are practically unusable),

- various sensors and measuring elements, which use rigidity of transferred materials and products.

When robotizing workplaces in textile industry, it is very difficult to apply industrial robots in their usual form. Problems can be divided into several categories:

Service operations - increasing speed and capacity of textile machines make great demands on physical ability of operators. E.g. a spindleless spinning machine has such high speed and drawing-off speed that the operator cannot reliably provide the exchange of wound bobbins without stopping the spinning at certain place and making a quality spinning-in. In these operations software-controlled automats are used - robotized workplaces equipped with single-purpose industrial robot. Manipulation with material - e.g. packaging of bobbins or their placing on taking off pallets (Fig.7).

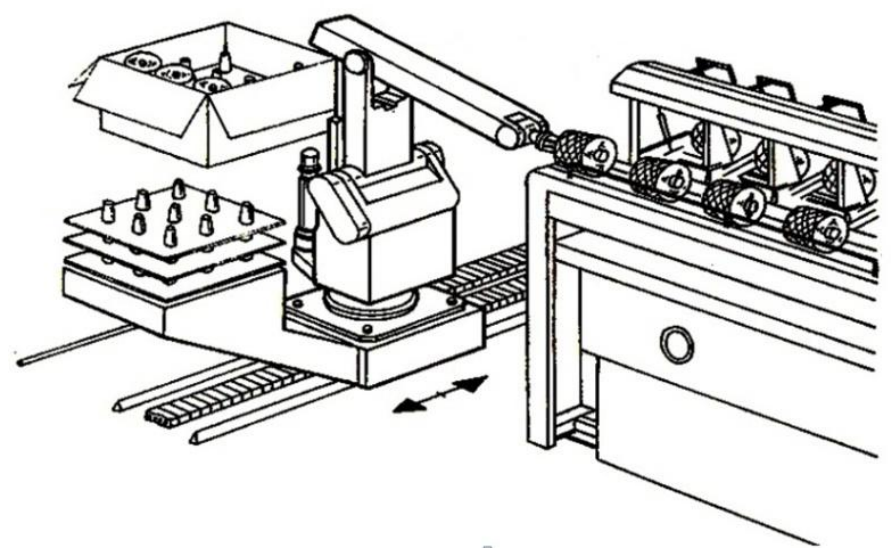

Fig.7. Packaging and dyeing of bobbins 


\section{Clothing production}

Over the years all world producers of sewing technologies have paid a lot of attention to mechanization and automation of sewing process. Existing development has seen various types of semi-automatic machines, automats and first robotized workplaces - automatic lines, e.g. JET - SEW CLUPICKER used to bluff upper edge of a patch pocket, to bluff lower edge of a short sleeve, to sew-on inner-lining on a cuff, etc.

Analysing existing technical development we can see that clothing technology has lead to strict expediency with high demands on quality and labour productivity. However, this technical development lags behind the modern clothing industry with high technology which is able to decrease high demands on workforce, and so it should concentrate on complex approach in these areas:

1. Continuing automation of the cycle - development of automated technology to make clothes parts.

2. Gradual automation of production sections, production lines, development of equipment for gradual automation of the whole product.

3. Alternative technologies - fixation, shaping, sewing replacement.

4. Improvement of control process by computerization.

New development requires flexible automation, or to increase automation with respect to production flexibility. By flexible production system we mean a line of production facilities which are so interconnected by common transport and control system that on one hand they provide the production automatically and on the other hand various technological operations on various products can be done within certain production.

One of the main reasons why existing elements of robotization and mechanization penetrate clothing production so slowly are especially specific conditions of production itself and physical - mechanical properties of processed materials.

These properties of clothing textile materials include:

- insufficient toughness, high permeability,

- strong surface adherence, low weight of material - gravitation force is not strong enough for releasing from manipulation tool,

- material's ability to get and keep electric charge,

- high elasticity and compliance of textile material.

Other restricting factors, which hinder immediate application of current elements of robotization and mechanization, are especially:

- fast changes in assortment concerning sort and size,

- a lot of changes in style of manufactured clothes,

- distinction in mode of transport and interstage transport,

- necessary control of the product while processing,

- high share of human factor while processing (mainly in link process),

- occurrence of irregularities (e.g. qualitative fault of clothing material, 
- faulty processing in preceding operations,

- change of physical and geometrical properties after processing, etc.)

- small operation space in the plant, unsolved problem of anchoring elements for textile materials, etc.

Current industrial way of clothes production, which involves more technological processes, can be characterised by high degree of labour division, high share of elementary manual operations, and high degree of production continuity and interconnection of workplaces according to manufacturing tact.

Next factor, which affects production rhythm, decreases labour productivity and lowers the volume of productionis sensitivity to irregularities and changes.

Ready-made production according to technological processes can be divided into 5 groups:

1. production preparation and cutting,

2. sewing,

3. ironing,

4. finishing,

5. transport and storing.

Each of these groups has its own problems from the automation point of view, but the largest and the most significant is the second group.

A lot of kinds of sewing machines are used in sewing. Each of these machines requires a special operation, though some partial operations are automated (guiding the panel while sewing, putting it away, putting it in, thread cutting, etc.)

The operator fills several tasks which can be divided into 4 parts:

1. preparation,

2. taking the panel and feeding the machine,

3. sewing (guiding of sewn material while sewing),

4. gripping of the panel and putting it away.

An analysis of work operations on a number of products has revealed percentage of time intervals for particular operations. The result is that the most significant operations are: taking the panel and feeding the sewing machine (82\%), and guiding of sewn material while sewing $(71 \%)$.

From the research of patent and scientific literature as well as from various experiments it is clear that separation and lifting of cloth parts from the layer can be done in different ways, e.g. by

- adhesive tape (ROBOT - TEX),

- small needles (Rimoldi),

- clamps (Singer, Juki),

- hollow needles (POLYTEX),

- combination of airflow and vacuum 

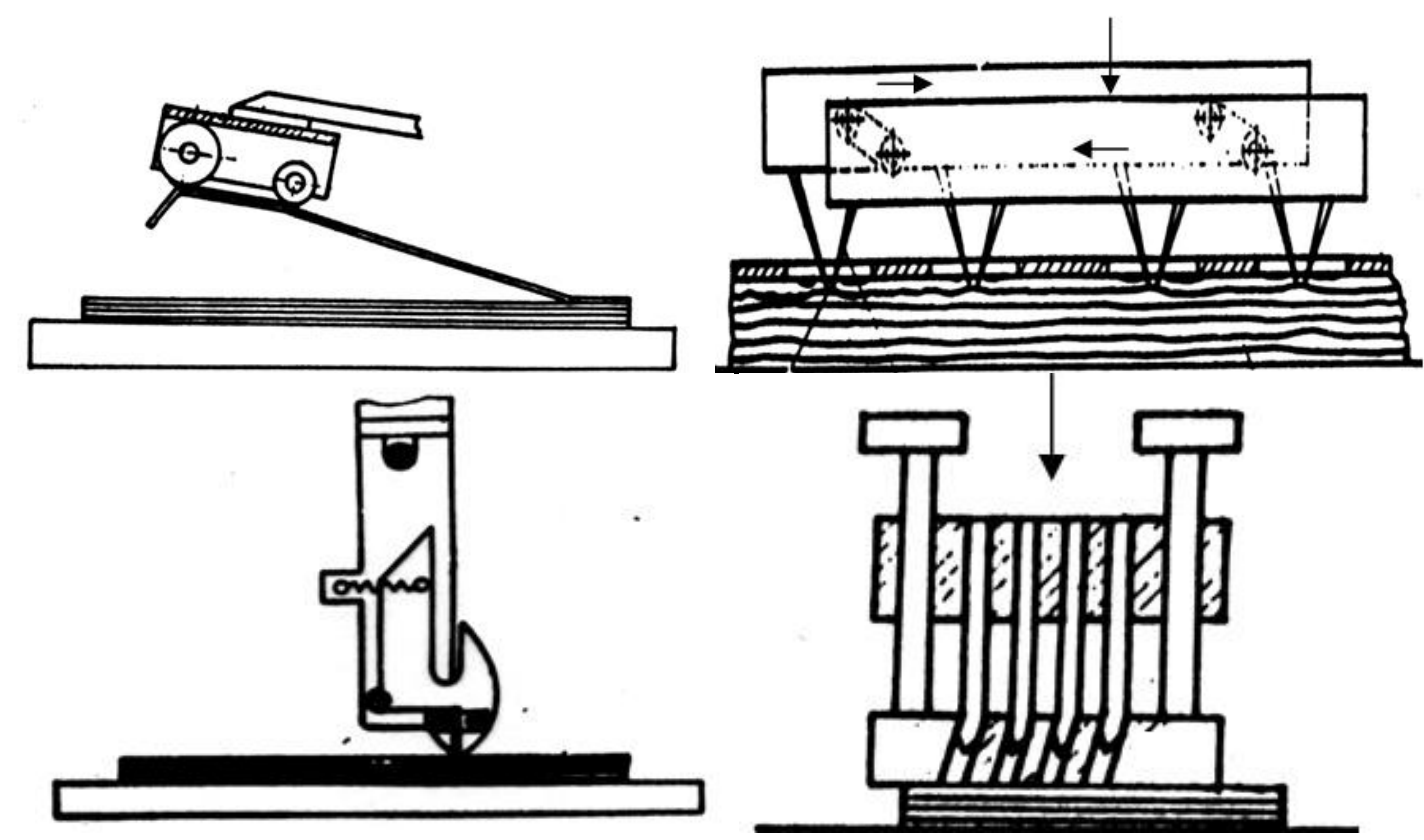

Fig.8. Different possibilities of handling sheets of fabric

There isstill a lot of problems with utilizing of robots and manipulators in clothing production due to

- textile material properties

- technical parameters of possible machinery that can be used, but

- high capital costs to equip robotized sewing workplace as well.

However, the issue of simple manipulators use, or the use of simple construction manipulation devices is still actual due to high share of human labour and its relatively low value as well as the necessity to automate some decisive work operations and so lower negative subjective effect on production quality.

Mechanized operations in sewing processes

The analysis of sewing process has revealed that sewing motions, which can be automated, are done mostly in straight line.

The most frequent are:

- Pressing of sewn material - is an operation where the material is pressed by a presser plate - when sewing small parts (collars, cuffs,...) or a presser bar - when sewing long parts.(Fig.9)
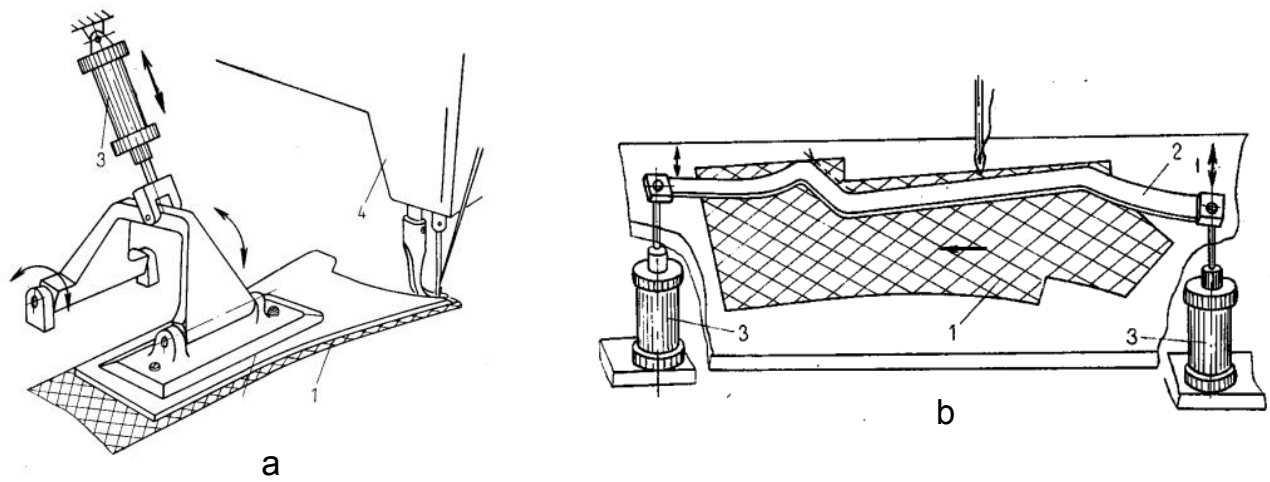

Fig. 9. Pressing of material: a- Pressing of template on a collar,b- Pressing by guidebar 
- Feeding of sewn material - is operated while sewing or after its finishing. Complementary feed is the most commonly performed by conveyor, feeding wheel, two feeding belts, etc. (Fig.10) It is used for buttoning, sewing-on buttons. Belts have serrated surface and are moved by mechanical gear.
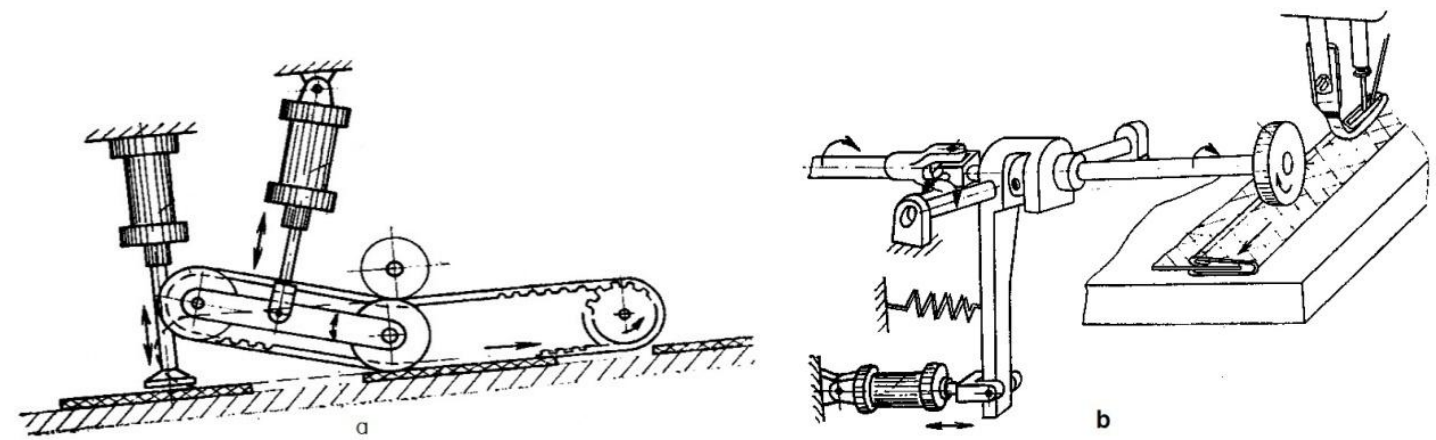

Fig. 10. Material feeding: a- using feeding belt, b- using feeding wheel

- Material transfer - is done when sewn material is to change its position Following motions can be performed :

- rectilinear feed of a small clothing component (Fig.11/a),

- angular rotation of a small clothing component (Fig.11/b),

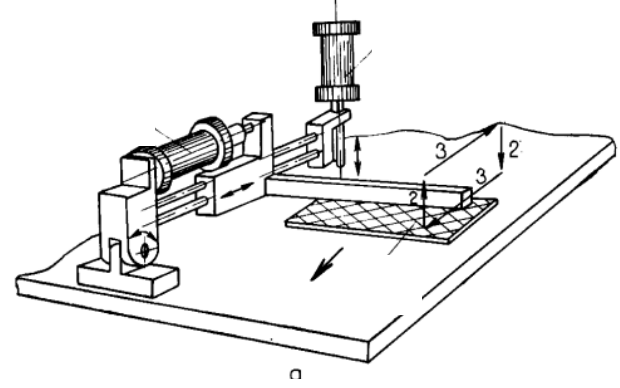

a

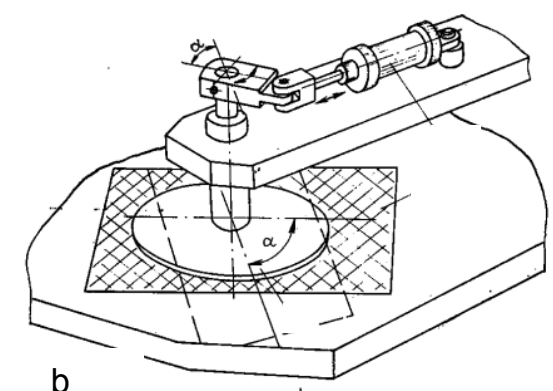

b

Fig. 11. Material transter: a- small parts feed with interval motion, b- turning over small parts

Basically, in all these cases simple, single-purpose manipulators are used. (Barborak, 2009)

\section{Application of robots in special technology}

Special technology has its important and unique position in machine engineering production especially due to its specific deployment. That is why an exceptional attention is paid to this problem in range of Special machine engineering study at the first stage.Production of search, robot-aided vehicles started with the aim to reach the places, which were inaccessible for a man in other way. Development of such vehicles started with development of spatial research at the end of sixties. The first such operational device was the Lunokhod1 (Fig. 12), which landed on the Moon 
in 1970. This robot-aided vehicle was mostly covered with solar panels; it carried two TV cameras, a spectrometer for a chemical analysis and other devices.

Fig.12. Lunokhod 1

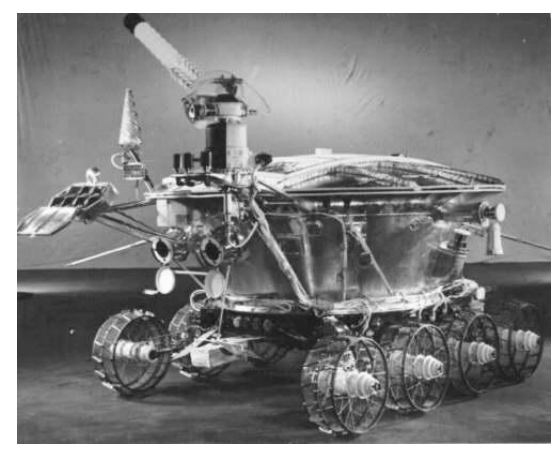

For a scientific research these vehicles are the most often used in spatial program of the U.S. agency for spatial research N.A.S.A. Nowadays two exploring vehicles Spirit and Opportunity are in their exploring mission on Mars (Fig. 13).

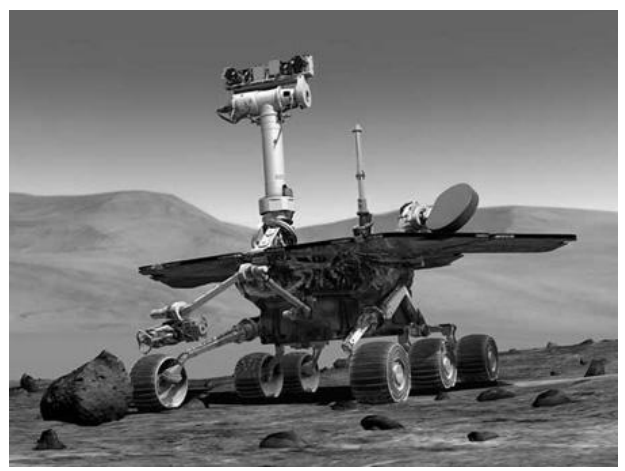

Fig.13. Mars rover Opportunity

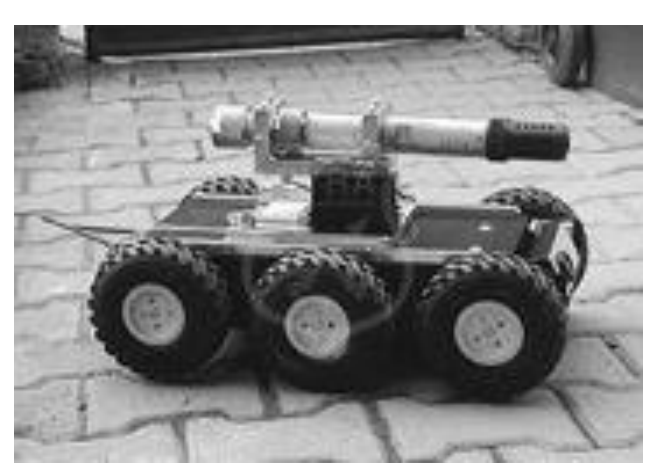

Fig.14. Small explorational robot

The next example on how to use a special-purpose robot is a reconnaissance vehicle for pyrotechnic purposes (Fig. 14) - a small remotely controlled robot was developed and designed as a reconnaissance vehicle, which is able to reach narrow and confined areas, under the vehicles with a low clearance, narrow aisles in aircraft, buses, trains, etc. Its robust and highly rigid construction enables using of efficient water disruptor or a shotgun for an efficient disposal of suspicious packets or other devices.

Other special robots include for example reconnaissance, combat, transport and demining robots (Fig.15).
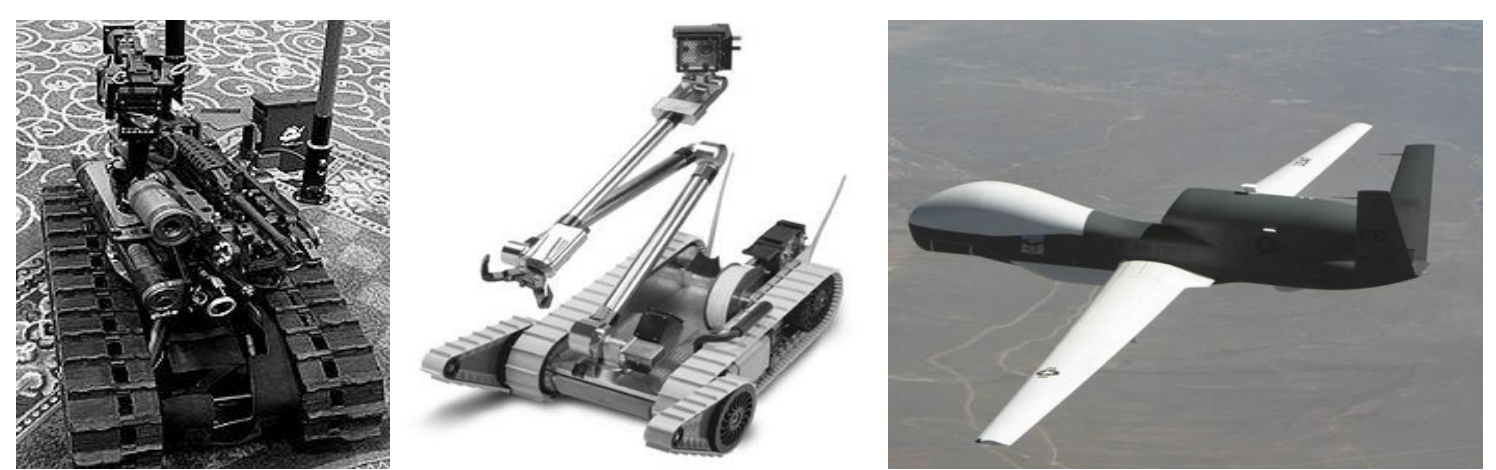

Fig. 15. Remotely operated reconnaissance robots 
The task of reconnaissance robots for military purposes is to reach areas, which are too dangerous for military personnel and to transfer information, through cameras and microphones, about situation on the battlefield. These robots have no artificial intelligence,they are remotely controlled by an operator.

\section{Examples of an application of special robots and handler in various industries}

Various industries require different constructions, reliability and a general effectivity of robot deployment. Therefore in non-machinery industries the Robots have different shape, construction, dynamics of motions etc. The following pictures show examples of such robots in practice (Fig.16).

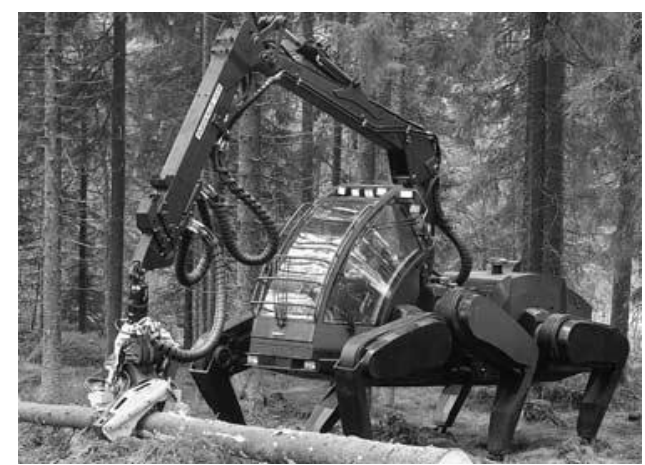

Fig. 16.Walking handler in silvicultural production

This presentation was developed in range of solution of KEGA No. 3/7285/09 program.

\section{References}

Barborak O., Demec P., Barborakova S., Turigyn Y. (2009). Unique Aspects of Robotizaion Elements Introduction in Some Industrial Branches, Bulletin of Izhevsk State University, No 3 (43) 2009, ISSN 1813 - 7903

Barborak O. (2009). Zaklady robotizacie mechanicke aspekty robotov a manipulatorov, Trencianska univerzita A. Dubceka v Trencíne, Trencin, 2009, ISBN 978-80-8075-377-1

Barborak O. (2010). Robotics in Special Technology Quality assurance in engineering education.IV. International conference, Izhevsk, Russia, 21. 23.4.2010, ISBN 978-5-7526-0437-9 (T.1)

Liptak P., Barborak O. (2006). Automatizacia a roboticke systemy v specialnej technike, 8. celostatna konferencia s medzinarodnou ucastou Automatizacia/Robotika v teorii a praxi ROBOTEP 2006, TU Kosice, 31.5.2.6.2006, Jasns . Nizke Tatry, SR, ISSN 1335-2393

Stollmann V., Bozek P., Barborak O., Nascak L., Walekova G. (2008). Virtual Technologies For Specialized Robotic Workplaces, 19 th International DAAAM Symposium "Intelligent Manufacturing \& Automation: Focus on Next Generation of Intelligent Systems and Solution", 22.-25..10.2008, Trnava, Slovakia, ISBN 978-3-901509-68-1, ISSN 1726-9679, pg. 1319-1320 